\title{
NADPH oxidase activation contributes to native low-density lipoprotein-induced proliferation of human aortic smooth muscle cells
}

\author{
Il Hwan Park ${ }^{1,7}$, Hye Mi Hwang, 2,7 , Byeong Hwa Jeon ${ }^{3}$, Hyung-Joo Kwon ${ }^{4}$, Kwang Lae Hoe ${ }^{5}$, \\ Young Myeong $\mathrm{Kim}^{6}$ and Sungwoo Ryoo ${ }^{2}$
}

\begin{abstract}
Elevated plasma concentration of native low-density lipoprotein (nLDL) is associated with vascular smooth muscle cell (VSMC) activation and cardiovascular disease. We investigated the mechanisms of superoxide generation and its contribution to pathophysiological cell proliferation in response to $\mathrm{nLDL}$ stimulation. Lucigenin-induced chemiluminescence was used to measure nLDL-induced superoxide production in human aortic smooth muscle cells (hAoSMCs). Superoxide production was increased by nicotinamide adenine dinucleotide phosphate (NADPH) and decreased by NADPH oxidase inhibitors in nLDL-stimulated hAoSMC and hAoSMC homogenates, as well as in prepared membrane fractions. Extracellular signal-regulated kinase $1 / 2$ (Erk1/2), protein kinase C- $\theta$ (PKC $\theta$ ) and protein kinase C- $\beta$ (PKC $\beta$ ) were phosphorylated and maximally activated within $3 \mathrm{~min}$ of $\mathrm{nLDL}$ stimulation. Phosphorylated Erk1/2 mitogen-activated protein kinase, PKC $\theta$ and PKC $\beta$ stimulated interactions between p47phox and p22phox; these interactions were prevented by MEK and PKC inhibitors (PD98059 and calphostin C, respectively). These inhibitors decreased nLDL-dependent superoxide production and blocked translocation of p47phox to the membrane, as shown by epifluorescence imaging and cellular fractionation experiments. Proliferation assays showed that a small interfering RNA against p47phox, as well as superoxide scavenger and NADPH oxidase inhibitors, blocked $\mathrm{nLDL}$-induced hAoSMC proliferation. The $\mathrm{nLDL}$ stimulation in deendothelialized aortic rings from C57BL/6J mice increased dihydroethidine fluorescence and induced p47phox translocation that was blocked by PD98059 or calphostin C. Isolated aortic SMCs from p47phox ${ }^{-1-}$ mice (mAoSMCs) did not respond to $\mathrm{nLDL}$ stimulation. Furthermore, NADPH oxidase 1 (Nox1) was responsible for superoxide generation and cell proliferation in nLDL-stimulated hAoSMCs. These data demonstrated that NADPH oxidase activation contributed to cell proliferation in nLDL-stimulated hAoSMCs.
\end{abstract}

Experimental \& Molecular Medicine (2015) 47, e168; doi:10.1038/emm.2015.30; published online 12 June 2015

\section{INTRODUCTION}

Vascular smooth muscle cells (VSMCs) play an important role in the progression of atherogenesis and in the development of postangioplasty restenosis through proliferation and migration. ${ }^{1}$ According to the 'response-to-injury' model, hypertension and a family of low-density lipoprotein (LDL) are believed to be major independent risk factors for the development of atherosclerosis. ${ }^{1,2}$ Although modified LDL, such as oxidized- and glycated-LDL, is more atherogenic to vascular cells than native LDL (nLDL), ${ }^{1,3,4} \mathrm{nLDL}$ induces VSMC proliferation and is the major mitogenic and proatherogenic molecule in the lesions where endothelial dysfunction occurs. ${ }^{5-7}$

In nLDL-induced VSMC proliferation, the extracellular signal-regulated kinase 1/2 (Erk1/2) signal cascade is one of the most important pathways, and the activation of protein kinase $\mathrm{C}$ (PKC) $\beta$ and $\theta$ is also necessary for nLDL-induced cell proliferation by upregulating transcription factors rapidly and transiently, such as the early growth response gene (Egr)- $1 .{ }^{8,9}$ Furthermore, acute formation of reactive oxygen species (ROS) appears to be important for mitogenic signaling of nLDL in VSMCs. ${ }^{6}$ Indeed, atherosclerosis is associated with increased

\footnotetext{
${ }^{1}$ Department of Cardiothoracic Surgery, Yonsei University Wonju College of Medicine, Wonju, Korea; ${ }^{2}$ Department of Biology, College of Natural Sciences, Kangwon National University, Chuncheon, Korea; ${ }^{3}$ Infectious Signaling Network Research Center, Department of Physiology, School of Medicine, Chungnam National University, Daejeon, Korea; ${ }^{4}$ Department of Microbiology, School of Medicine, Hallym University, Chuncheon, Korea; ${ }^{5}$ Department of New Drug Discovery and Development, Chungnam National University, Daejeon, Korea and ${ }^{6}$ Department of Molecular and Cellular Biochemistry, School of Medicine, Kangwon National University, Chuncheon, Korea

${ }^{7}$ These authors contributed equally to this work.

Correspondence: Professor S Ryoo, Department of Biology, Kangwon National University, Kangwondae-gil 1, Chuncheon, Kangwon-do 200-701, Korea. E-mail: ryoosw08@kangwon.ac.kr

Received 30 September 2014; revised 23 January 2015; accepted 3 February 2015
} 
intracellular oxidative stress and the activation of Erk $1 / 2$ and $\mathrm{PKC}$ as an important regulator of cell growth.

Nicotinamide adenine dinucleotide phosphate (NADPH) oxidase is an important enzymatic source of superoxide anion in the vasculature; ${ }^{10-12}$ its activation influences contraction, growth, apoptosis and VSMC extracellular matrix protein production. ${ }^{13-15}$ However, the signaling cascades between the kinases involved in cell proliferation and ROS generation need to be determined in nLDL-stimulated human aortic smooth muscle cells (hAoSMCs).

We tested the hypothesis that superoxide production caused by the activation of NADPH oxidase plays a key role in nLDLstimulated VSMC proliferation. Here, we demonstrated that nLDL stimulation induced the independent activation of Erk1/2 and PKC $\beta$ and PKC $\theta$ that participate in the translocation of cytosolic p47phox to the plasma membrane. NADPH oxidase-dependent superoxide production was essential for proliferation in nLDL-stimulated hAoSMCs. These findings may partially explain a new mechanism for the mitogenic effect of NADPH oxidase in terms of hypercholesterolemia, oxidative stress and VSMC proliferation.

\section{MATERIALS AND METHODS}

\section{Materials}

Dihydroethidine (DHE), lucigenin, rottlerin (Rotln), PD98059, SB203580, myristoylated PKC $\theta$ pseudosubstrate $(\mathrm{mPKC} \theta)$ and $\mathrm{PKC} \beta$ inhibitor (3-(1-(3-imidazol-1-ylpropyl)-1H-indol-3-yl)-4-anilino-1Hpyrrole-2,5-dione) were purchased from Calbiochem (Billerica, MA, USA). Phospho-PKC $\theta$, phospho-Erk1/2 mitogen-activated protein kinase (MAPK) and $\alpha$-actin antibodies were purchased from Cell Signaling Technology (Danvers, MA, USA), and p47phox, p22phox, NADPH oxidase 1 (Nox1), Nox2, Nox4 and NoxO1 antibodies and small interfering RNAs (siRNAs) were purchased from Santa Cruz Biotechnology (Santa Cruz, CA, USA). $\mathrm{Cl}^{-}$channel blocker, 4,4'diisothiocyanostilbene-2,2'-disulfonic acid (DIDS) was purchased from Calbiochem. All other reagents were purchased from Sigma (St Louis, MO, USA), unless otherwise stated.

\section{Cell culture and animals}

The hAoSMCs were purchased and maintained in an SmGM-2 Bullet kit medium (Clonetics, San Diego, CA, USA) at $37^{\circ} \mathrm{C}$ in $5 \% \mathrm{CO}_{2}$. For all experiments, hAoSMCs were incubated for $24 \mathrm{~h}$ with Dulbecco's modified Eagle's medium (DMEM; Gibco, Grand Island, NY, USA) containing $0.1 \%$ fetal bovine serum (Gibco) before stimulation. Male wild-type (WT) C57BL/6J (Daehan Biolink, Umsung, Korea) and $\mathrm{p}_{4} 7 \mathrm{phox}^{-1-}$ mice with the same genetic background as the WT were anesthetized with isoflurane (Baxter, IL, USA), and SMCs from aortic vessels were isolated using the explant technique on gelatincoated culture dishes. The institutional review board at Kangwon National University (Chuncheon, Korea) approved this study in accordance with the Guide for the Care and Use of Laboratory Animals

\section{Isolation of $\mathrm{nLDL}$}

$\mathrm{nLDL}$ (density $1.019-1.063 \mathrm{~g} \mathrm{~m}^{-1}$ ) was isolated from the plasma of normocholesterolemic subjects (serum cholesterol $<6.2 \mathrm{~mm}$ ) by differential ultracentrifugation, as previously described. ${ }^{16}$ Particular cautions were taken during LDL manipulation and storage to maintain
nLDL integrity and to prevent LDL oxidation. The endotoxin contents were below the detection limit $\left(1 \mathrm{ng} \mathrm{ml}^{-1}\right)$, as measured by an endotoxin assay kit (Pharmingen, Fallbrook, CA, USA). The study protocols were approved by the institutional ethics review board at Kangwon National University. Commercial LDL and oxidized LDL prepared by $\mathrm{CuSO}_{4}$ reaction were purchased from Intracel (Frederick, MD, USA). Thiobarbituric acid reactive substances (TBARS) assay of prepared LDLs from three independent experiments, using malondialdehyde as a standard, showed a mean value $(-0.60 \pm 0.06 \mu \mathrm{M})$ that was comparable to that of commercially available nLDL $(-0.55 \pm 0.04 \mu \mathrm{M})$ and substantially lower than oxidized LDL $(7.95 \pm 0.60 \mu \mathrm{M})$, indicating that LDL did not undergo oxidation. Prepared LDL was not oxidized during agarose gel electrophoresis because the mobility of the prepared LDL was significantly slower than that of the oxidized LDL.

\section{Intracellular superoxide measurement using lucigenin}

The serum-starved cells $\left(1 \times 10^{5}\right.$ cells $)$ were harvested by centrifugation $(800 \mathrm{~g}$ for $5 \mathrm{~min}$ ) after trypsin treatment and then incubated for 30 min with various inhibitors. Lucigenin-induced chemiluminescence $(5 \mu \mathrm{M})$ was recorded using a luminometer (Lumat LB9507, Berthold Technol., Bad Wildbad, Germany) in Krebs-HEPES ((in mм) $\mathrm{NaCl}$ 99.01, $\mathrm{KCl}$ 4.69, $\mathrm{CaCl}_{2}$ 1.87, $\mathrm{MgSO}_{4}$ 1.2, NaHEPES 20, $\mathrm{K}_{2} \mathrm{HPO}_{4} 1.03$, $\mathrm{NaHCO}_{3} 25, \mathrm{D}-[+]$ glucose $11.1 ; \mathrm{pH}$ 7.4) buffer, with or without nLDL stimulation $\left(100 \mu \mathrm{g} \mathrm{ml}^{-1}\right)$. Chemiluminescence intensity was measured for $5 \mathrm{~min}^{17}$ in all experiments, and the values were expressed as relative lucigenin units per $\min \left(\mathrm{RLU} \mathrm{min}^{-1}\right)$.

\section{Proliferation assay}

Cell proliferation was assessed using WST-1 (4[-3-(4-iodophenyl)-2(4-nitrophenyl)-2H-5-tetrazolio]-1,3-benzene disulfonate) according to the manufacturer's protocol (Roche, Branford, CT, USA). Briefly, $\sim 1 \times 10^{5}$ cells were incubated in 96-well plates and starved with serum-free DMEM for $24 \mathrm{~h}$. After the cells were treated with appropriate inhibitors and/or nLDL, $10 \mu \mathrm{l}$ of WST-1 reagent was added to each well. Absorbances were read at 450 and $650 \mathrm{~nm}$.

\section{Isolation of cytosolic and membrane fractions}

Treated cells were homogenized twice in Tris buffer $(25 \mathrm{~mm}, \mathrm{pH} 7.4$, protease inhibitors (Roche) $250 \mathrm{~mm} \mathrm{NaCl}, 0.1 \% \beta$-mercaptoethanol and $3 \mathrm{~mm}$ EDTA) for $3 \mathrm{~min}$ and centrifuged at $1000 \mathrm{~g}$ for $10 \mathrm{~min}$ to remove cell debris and intact cells. The supernatant was centrifuged at $21000 \mathrm{~g}$ for $45 \mathrm{~min}$ at $4{ }^{\circ} \mathrm{C}$. Protein $(20 \mu \mathrm{g})$ from cytosolic and membrane fractions, respectively, was examined for superoxide generation using luminometer and for $\mathrm{p} 47 \mathrm{phox}$ translocation from the cytosol to the membrane using western blot analysis. The thoracic aorta was dissected from the killed mice $(\mathrm{C} 57 \mathrm{BL} / 6)$, cut into $3 \mathrm{~mm}$ rings and incubated overnight in phenol-red free DMEM $(0.1 \%$ fetal bovine serum and $1 \times$ antibiotics $)$ containing $\mathrm{nLDL}\left(100 \mu \mathrm{g} \mathrm{ml}^{-1}\right)$ and/or PD98059 or Rotln. The homogenates were fractionated into cytosolic and membrane fractions, as described above.

\section{Immunoprecipitation and western blot analysis}

Lysates from hAoSMCs were immunoprecipitated with the primary antibodies overnight at $4^{\circ} \mathrm{C}$ (RIPA lysis buffer, Upstate, New York, NY, USA). After incubation with protein $\mathrm{A} / \mathrm{G}$ agarose for $4 \mathrm{~h}$ at $4{ }^{\circ} \mathrm{C}$, the beads were washed three times with lysis buffer. Then, the beads were placed in SDS sample buffer $(62.5 \mathrm{~mm}$, Tris- $\mathrm{HCl}, \mathrm{pH} 6.8,2 \%$ SDS, $10 \%$ glycerol, $50 \mathrm{~mm}$ dithiothreitol, $0.01 \%$ bromophenol blue), resolved on $10 \%$ SDS-PAGE and transferred to a nitrocellulose 
membrane (Bio-Rad, Hercules, CA, USA). The membrane was incubated with antibodies and visualized with an enhanced chemiluminescence system (Amersham Pharmacia, Missouri, TX, USA). For western blot analysis, cells were washed three times with phosphatebuffered saline and lysed in the SDS sample buffer. Proteins were separated by SDS-PAGE, transferred and then detected with an enhanced chemiluminescence system. The intensity of each protein was analyzed using ImageJ software (NIH, Bethesda, MD, USA).

\section{Immunofluorescence microscopy}

Pretreated cells were grown on gelatin-coated glass, permeabilized and fixed with $3.7 \%$ paraformaldehyde plus $0.5 \%$ Triton X-100 in phosphate-buffered saline. The cells were rinsed with phosphate-buffered saline and incubated with a polyclonal antibody against p47phox (Cell Signaling Technology) and then again with fluorescein isothiocyanateconjugated anti-rabbit IgG antibody. The washed cells were imaged with an epifluorescence microscope (Olympus $1 \times 81$, Tokyo, Japan)

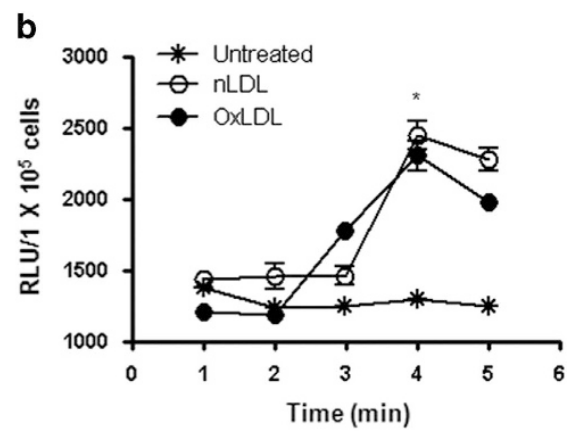

Figure 1 Native low-density lipoprotein ( $\mathrm{nLDL}$ ) induced superoxide production in human aortic smooth muscle cells (hAoSMCs). The $\mathrm{nLDL}$ stimulation $\left(100 \mu \mathrm{g} \mathrm{ml}^{-1}\right)$ increased the slope of dihydroethidine $(\mathrm{DHE} ; 10 \mu \mathrm{m})$ fluorescence intensity that was abolished by preincubation with polyethylene glycol-conjugated superoxide dismutase (PEG-SOD, $500 \mathrm{U} \mathrm{ml}^{-1}$ ) (a, * vs untreated, $P<0.01, n=4$; \# vs $\mathrm{nLDL}$, $P<0.01, n=4)$. The $n L D L$ treatment increased lucigenin-induced chemiluminescence in a time-dependent manner (b, * vs untreated, $P<0.01, n=5)$. Oxidized LDL $\left(50 \mu \mathrm{g} \mathrm{ml}^{-1}\right)$ was used as a control.
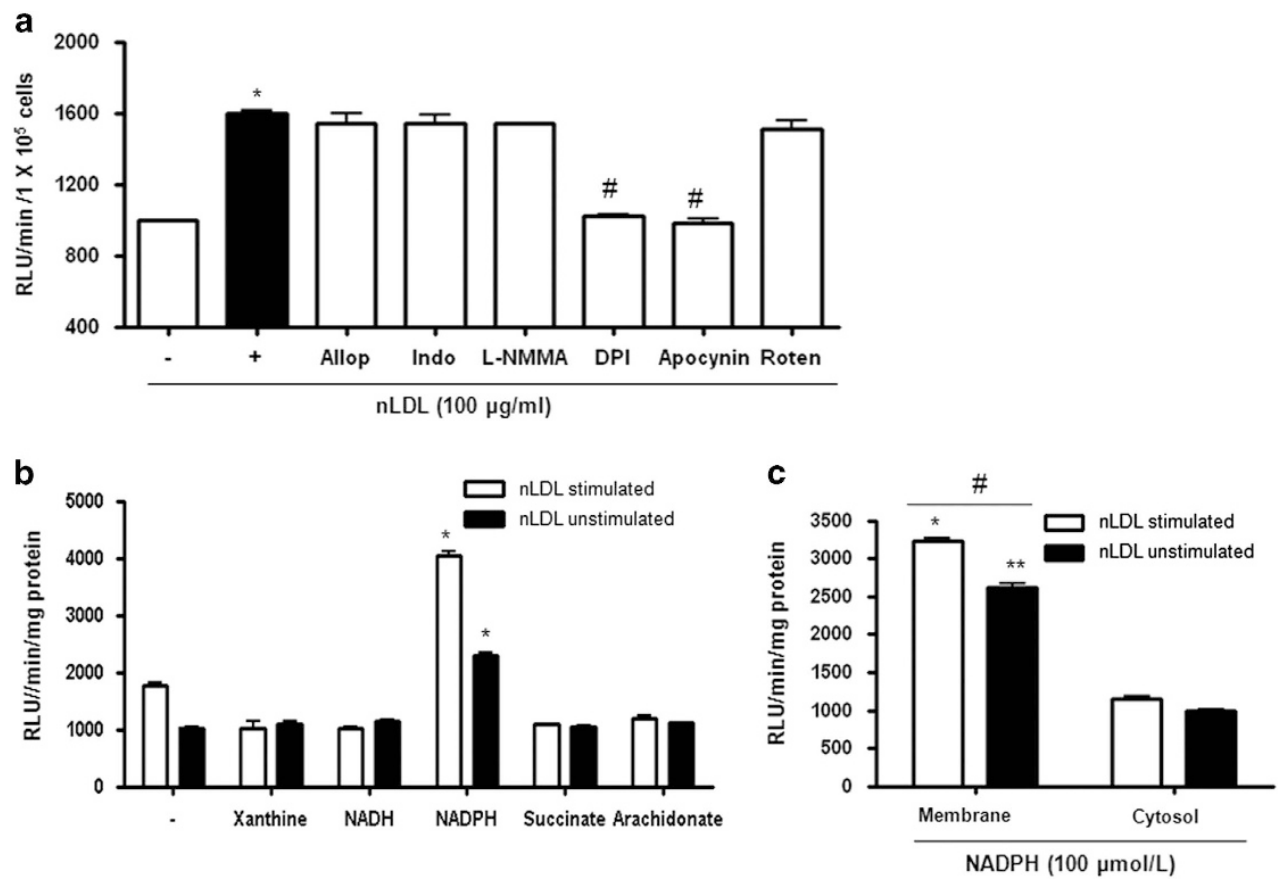

Figure 2 Native low-density lipoprotein ( $\mathrm{nLDL}$ ) increased superoxide production by activating nicotinamide adenine dinucleotide phosphate (NADPH) oxidase. (a) Human aortic smooth muscle cells (hAoSMCs) were stimulated with nLDL in the presence or absence of superoxideproducing enzyme inhibitors. NADPH oxidase inhibitors, diphenylene iodonium (DPI, $10 \mu \mathrm{m})$ and apocynin (100 $\mu \mathrm{m})$ attenuated the increase in $\mathrm{nLDL}$-dependent superoxide production (a, * vs untreated, $P<0.01, n=4$; \# vs $\mathrm{nLDL}, P<0.01, n=6$ ), but allopurinol (allop, $100 \mu \mathrm{m}$ ), indomethacin (indo, $10 \mu \mathrm{M}$ ), $\mathrm{N}^{\mathrm{G}}$-monomethyl-L-arginine (L-NMMA, $10 \mu \mathrm{M}$ ) and rotenone (roten, $100 \mu \mathrm{M}$ ) had no effect. (b) NADPH incubation of $\mathrm{nLDL}$-stimulated and -unstimulated hAOSMC homogenates ( $100 \mu \mathrm{m})$ increased superoxide generation (* vs untreated, $P<0.01, n=4)$, but xanthine, $\mathrm{NADH}$, succinate and arachidonic acid (100 $\mu \mathrm{m}$ each) did not affect superoxide generation. (c) The homogenates were separated into membrane and cytosolic fractions by centrifugation and incubated with NADPH as a substrate. The membrane fraction showed increase in NADPH-dependent superoxide production (* vs cytosol, $P<0.01, n=4$ ). Superoxide production was higher in the membrane fraction from nLDL-stimulated hAoSMCs compared with the control cells $(\# P<0.05, n=4)$. 

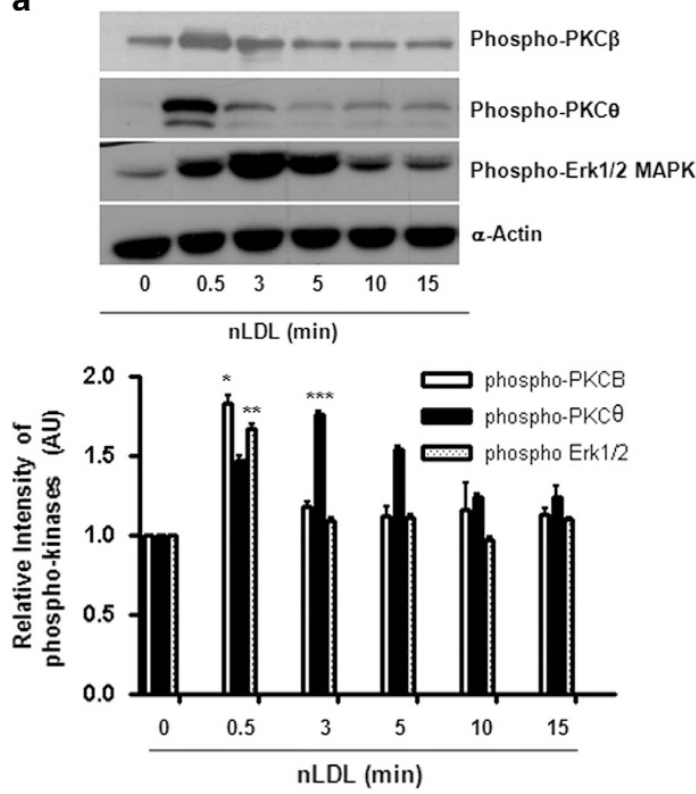

b

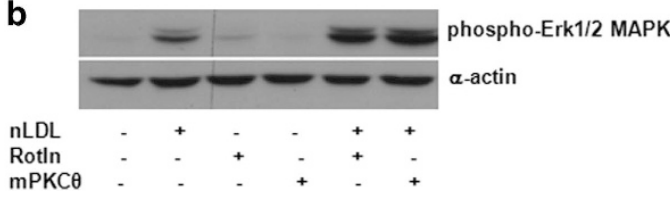

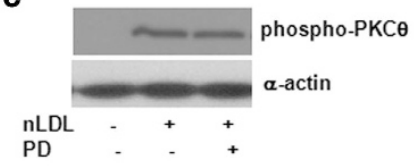

d

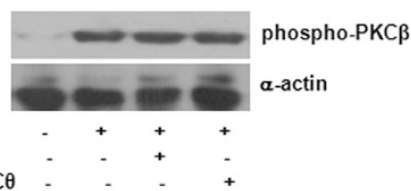

e

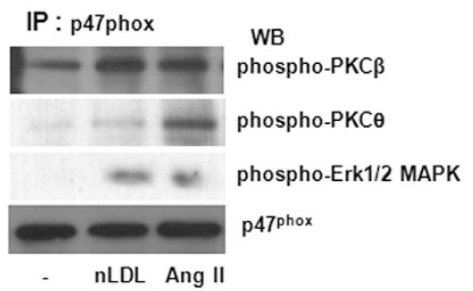

Figure 3 Native low-density lipoprotein ( $\mathrm{LLLL}$ ) stimulated independent phosphorylation of extracellular signal-regulated kinase 1/2 (Erk1/2) mitogen-activated protein kinase (MAPK) and protein kinase C (PKC) that were associated with p47phox-p22phox interaction. The nLDL stimulation induced maximal phosphorylation of Erk1/2 MAPK at $3 \mathrm{~min}$ and PKC at $30 \mathrm{~s}\left(\mathrm{a}\right.$, ${ }^{*}$ vs untreated, $* *$ vs untreated, ${ }^{* * *}$ vs untreated, $P<0.01, n=4)$. Erk1/2 MAPK phosphorylation was not blocked by the PKC inhibitors rottlerin (Rotln; $10 \mu \mathrm{m}$ ) and $\mathrm{mPKC \theta}$

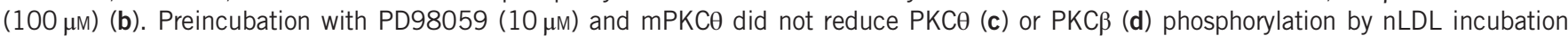
for 10 min. (e) Human aortic smooth muscle cell (hAoSMC) lysates were immunoprecipitated with antiserum against p47phox after nLDL stimulation. p47phox showed increased interaction with phosphorylated Erk1/2 MAPK, phosphorylated PKC $\theta$, and phosphorylated PKC $\beta$. Angiotensin II (10 nm, $10 \mathrm{~min})$ stimulation was used as a control. The representative blot was from three independent experiments.

equipped with an intensified camera (Clara CCD, Andor Technology, Belfast, UK) and a custom image acquisition program (Metamorph software, Molecular Devices, Foster, CA, USA).

\section{Microscopic estimation of superoxide production by DHE fluorescence probe}

Serum-starved cells in phenol red-free DMEM were labeled with DHE $(1 \mu \mathrm{M})$ for $10 \mathrm{~min}$, incubated with $\mathrm{nLDL}$ for $30 \mathrm{~min}$ and washed three times with HEPES buffer $\left(\mathrm{NaCl} 120 \mathrm{~mm}, \mathrm{KH}_{2} \mathrm{PO}_{4} 2.6 \mathrm{~mm}, \mathrm{KCl} 4 \mathrm{~mm}\right.$, $\mathrm{CaCl}_{2} 2 \mathrm{~mm}, \mathrm{MgCl}_{2} 0.6 \mathrm{~mm}$, HEPES $25 \mathrm{~mm}$ and glucose $14 \mathrm{~mm}, \mathrm{pH}$ 7.4). The thoracic aorta was dissected from the killed C57BL/6 mice, cleaned of fat and connective tissues and longitudinally trimmed to expose the endothelium. The endothelium was gently removed using a wooden stick, labeled with $1 \mu \mathrm{M}$ DHE for $10 \mathrm{~min}$, and stimulated with nLDL. Images were acquired using an 'up-light' epifluorescence microscope (Olympus, $10 \times$ objectives, excitation $488 \mathrm{~nm}$, emission $580 \mathrm{~nm}$ ), and fluorescence intensity was measured at different time intervals. ${ }^{17}$ The change in fluorescence over time was determined using linear regression in Origin (version 7.5, OriginLab, Northampton, MA USA), and the resulting slopes were used for statistical comparison.

\section{SiRNA transfection}

Transient transfection with siRNA against p47phox (sc-29422), Nox1 (sc-43939) and Nox2 (sc-35503) siRNA and control siRNA (sc-37007) was performed using an oligofectamine reagent, according to the manufacturer's instructions (Invitrogen, Carlsbad, CA, USA). Briefly, $8 \mu \mathrm{l}$ of oligofectamine was added to $17 \mu \mathrm{l}$ Opti-MEM I reduced serum media (Gibco), incubated for $5 \mathrm{~min}$ at room temperature, mixed with $180 \mu \mathrm{l}$ Opti-MEM medium containing siRNA $(6 \mu \mathrm{l})$ and further incubated for $15 \mathrm{~min}$. The siRNA-oligofectamine complex was then overlaid on cells (each well contained $1 \mathrm{ml}$ of serum-free media in a six-well culture dish). After a 6-h incubation, the serum concentration in the growth medium was returned to a $1 \times$ serum concentration (5\%) by adding $3 \times 0.5-\mathrm{ml}$ aliquots of media per well. The transfected cells were incubated for $36 \mathrm{~h}$, serum starved for $24 \mathrm{~h}$ and then stimulated with nLDL for $24 \mathrm{~h}$.

\section{Statistical analysis}

Values were presented as the mean \pm s.d. Statistical significance was assessed with an unpaired Student's $t$-test using GraphPad Prism 4.02 software (La Jolla, CA, USA). Statistical significance was set at $P<0.05$.

\section{RESULTS}

nLDL increased superoxide generation in hAoSMCs Stimulation with nLDL increased the slope of DHE fluorescence ( ${ }^{*}$ vs untreated, $1.04 \pm 0.09$ vs $1.70 \pm 0.13$ intensity s ${ }^{-1}$ ) that was attenuated by polyethylene glycol-conjugated 
a

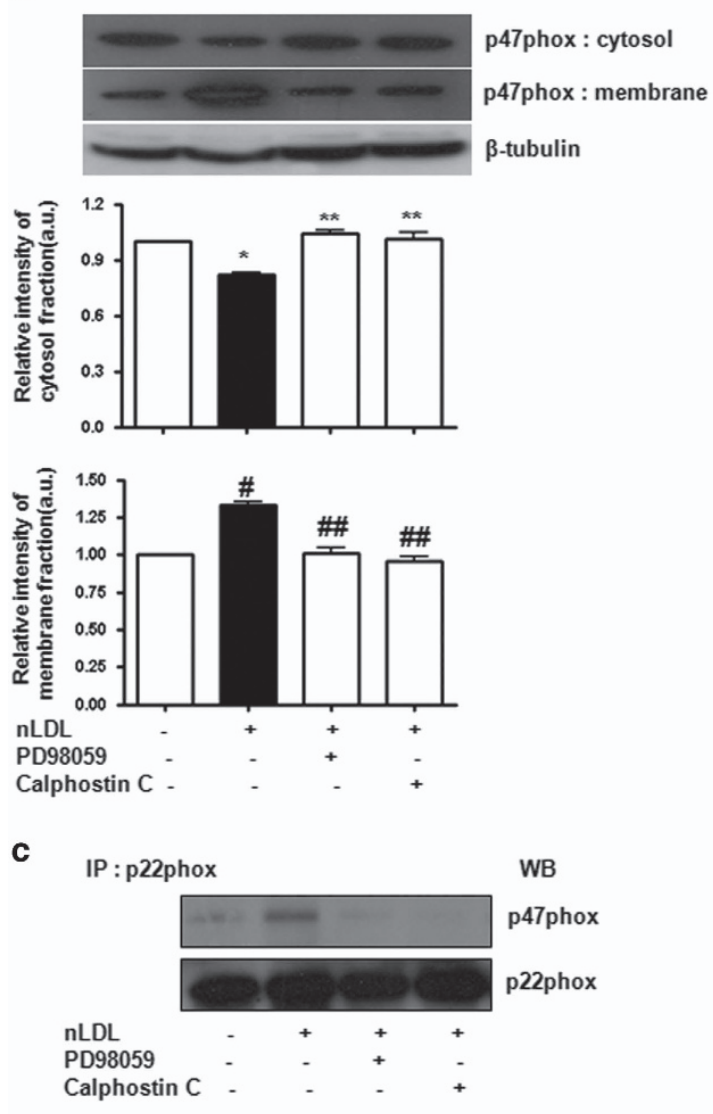

b
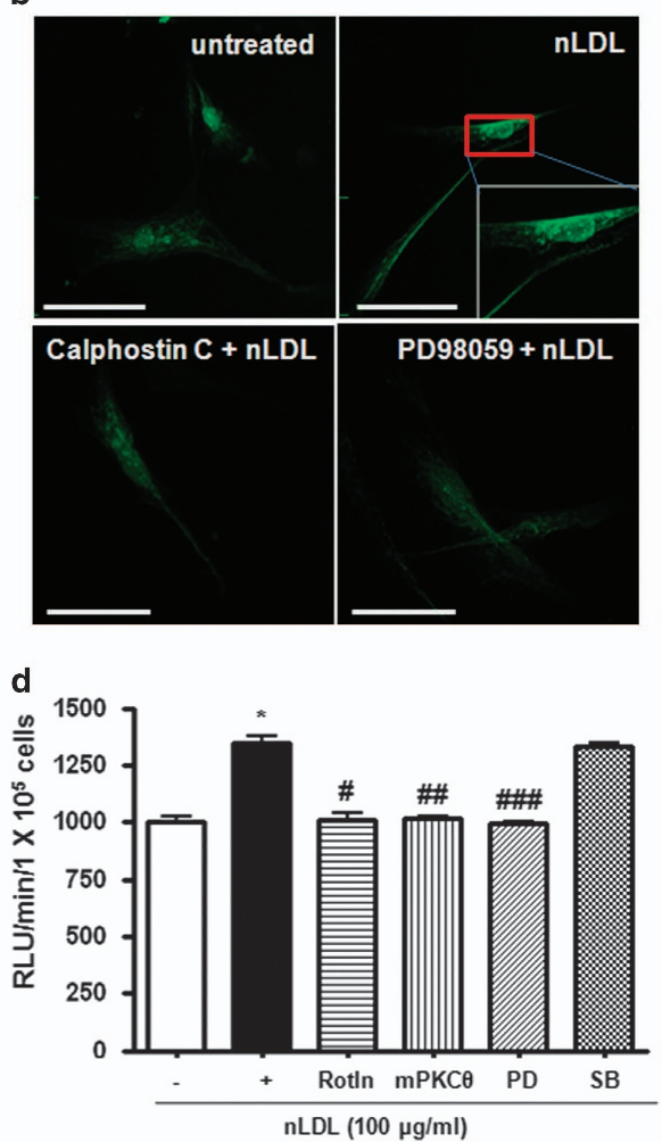

Figure 4 Extracellular signal-regulated kinase 1/2 (Erk1/2) mitogen-activated protein kinase (MAPK) and protein kinase C (PKC) activations regulated $\mathrm{p} 47 \mathrm{phox}$ membrane translocation and induced interaction of p47phox with p22phox. Membrane and cytosolic fractions from native low-density lipoprotein (nLDL)-stimulated or -unstimulated human aortic smooth muscle cells (hAoSMCs) in the presence and absence of PD98059 (10 $\mu \mathrm{m})$ or calphostin C (100 nm) were immunoblotted with antiserum against p47phox. Both inhibitors significantly decreased $\mathrm{p} 47$ phox content in the membrane fraction (a, * vs untreated, $P<0.05$; ** vs $\mathrm{nLDL}, P<0.05$; \# vs untreated, $P<0.01$; \#\# vs $\mathrm{nLDL}, \quad P<0.05 ; n=3$ ). (b) The nLDL-stimulated translocation of $\mathrm{p} 47 \mathrm{phox}$ was further confirmed using immunofluorescence images. Preincubation with calphostin C and PD980529, respectively, prevented this translocation. The image represents three separate experiments. The inset in the $\mathrm{nLDL}$ image shows $\times 2.5$ magnification of the point of interest. The bar indicates $5 \mu \mathrm{m}$. (c) The $\mathrm{nLDL}-$ stimulated p47phox translocation resulted in a complex formation with p22phox that was significantly prevented by PD98059 and calphostin C, respectively. The image represents three independent experiments. (d) The PKC inhibitors (rottlerin (Rotln, \# vs untreated, $P<0.01$ ) and mPKCe, \#\# vs untreated, $P<0.01$ ) and the Erk1/2 MAPK inhibitor PD98059 (PD, \#\#\# vs untreated, $P<0.01)$ stopped the $\mathrm{nLDL}$-induced superoxide generation, but the p38 MAPK inhibitor SB203580 (SB, $10 \mu \mathrm{m})$ did not have an effect $(n=4)$.

superoxide dismutase preincubation (\# vs nLDL, $1.01 \pm 0.03$ vs $1.70 \pm 0.13$ intensity $s^{-1}$, Figure 1a). The nLDL stimulation of hAoSMCs increased the lucigenin-dependent chemiluminescence from $1434 \pm 132$ to $2446 \pm 195 \mathrm{RLU} \mathrm{min}{ }^{-1}$ per $10^{5}$ cells (Figure 1b). Oxidized LDL was used as a positive control, and it increased the chemiluminescence intensity.

\section{nLDL induced superoxide production through NADPH}

oxidase activation

Stimulation with nLDL increased superoxide production $\left({ }^{*}\right.$ vs untreated, $1594 \pm 441$ vs $1012 \pm 21 \mathrm{RLU}^{-1} \min ^{-1}$ per $10^{5}$ cells) that was unaffected by preincubation with xanthine oxidase inhibitor, allopurinol, cyclooxygenase inhibitor, indomethacin, nitric oxide synthase inhibitor, $\mathrm{N}^{\mathrm{G}}$-monomethyl-L-arginine or mitochondrial electron transport chain inhibitor, rotenone.
However, flavin-containing enzyme inhibitor diphenylene iodonium and NADPH oxidase inhibitor apocynin reduced the nLDL-dependent superoxide production (nLDL vs DPI, $1594 \pm 44$ vs $1021 \pm 22 \mathrm{RLU} \mathrm{min}^{-1}$ per $10^{5}$ cells; nLDL vs apocynin, $1594 \pm 44$ vs $982 \pm 43 \mathrm{RLU} \mathrm{min}^{-1}$ per $10^{5}$ cells, Figure 2a).

The superoxide production in the nLDL-stimulated cell homogenates was 2.28-fold higher than that in the untreated cells $\left(1775 \pm 83 \mathrm{RLU} \mathrm{min}^{-1}\right.$ per $\mathrm{mg}$ protein). NADPH produced more superoxide than other substrates in the nLDL-stimulated $\left(4040 \pm 158 \mathrm{RLU} \mathrm{min}^{-1}\right.$ per $\mathrm{mg}$ protein) and unstimulated $\left(2284 \pm 97 \mathrm{RLU} \mathrm{min}^{-1}\right.$ per $\mathrm{mg}$ protein) homogenates (Figure 2b). As demonstrated in Figure 2c, the NADPH-dependent superoxide-producing enzyme was predominantly localized in the precipitated membrane fraction 
a

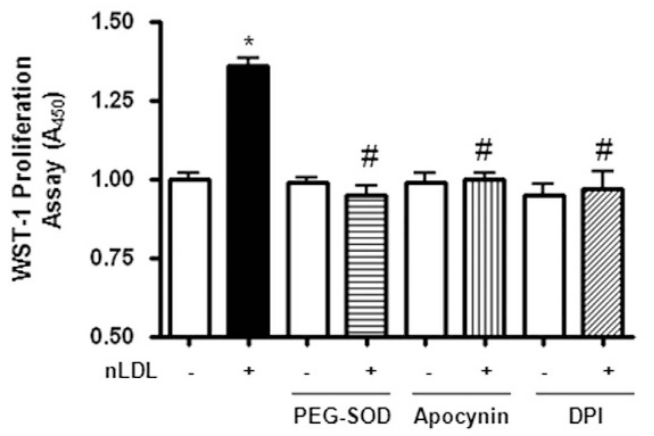

b

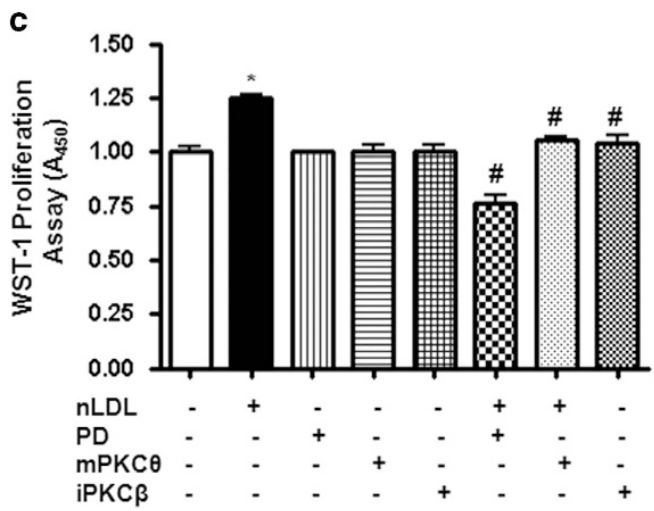

Figure 5 Inhibition of nicotinamide adenine dinucleotide phosphate (NADPH) oxidase abolished native low-density lipoprotein ( $\mathrm{nLDL}$ )-induced human aortic smooth muscle cell (hAoSMC) proliferation. (a) The $\mathrm{nLDL}$ induced proliferation of hAoSMCs (* vs untreated, $P<0.01, n=4$ ) that was abolished by polyethylene glycol-conjugated superoxide dismutase (PEG-SOD, $500 \mathrm{U} \mathrm{ml}^{-1}$ ) as well as the $\mathrm{NADPH}$ oxidase inhibitors apocynin $(100 \mu \mathrm{m}$ ) and diphenylene iodonium (DPI, $10 \mu \mathrm{m}$ ) (\# vs nLDL, $P<0.01, n=4$ ). (b, top) Small interfering RNA (siRNA) against p47phox transfection significantly decreased the p47phox protein levels. (b, bottom) siRNA preincubation prevented nLDL-induced proliferation of hAoSMCs (* vs untreated, $P<0.01$; \# vs nLDL, $P<0.01 ; n=4$ ). Cont, control siRNA. (c) Extracellular signal-regulated kinase 1/2 (Erk1/2) mitogen-activated protein kinase (MAPK), protein kinase C- $\beta$ (PKC $\beta$ ), and protein kinase C- $-\theta$ (PKC $\theta$ ) inhibitors abolished nLDL-induced proliferation of hAoSMCs (* vs untreated, $P<0.01 ; \#$ vs $n L D L, P<0.01 ; n=4$ ); iPKC $\beta$, inhibitor of PKC $\beta$.

( ${ }^{\star}$ vs nLDL cytosol, $3227 \pm 72$ vs $1145 \pm 84$ RLU min $^{-1}$ per mg protein; ${ }^{*}$ vs untreated cytosol, $2619 \pm 112$ vs $991 \pm 30$ RLU $\min ^{-1}$ per mg protein), and NADPH-driven superoxide production was higher in the nLDL-treated membrane fraction than in the untreated control.

\section{Stimulation with nLDL independently phosphorylated Erk1/2 MAPK, PKC $\theta$ and PKC $\beta$ that interacted with p47phox}

Given that superoxide generation occurred just 4 min after nLDL stimulation, we examined protein kinase phosphorylation at early time points. Stimulation with nLDL resulted in PKC $\beta$ and PKC $\theta$ phosphorylation after $30 \mathrm{~s}$ (Figure 3a), and PKC $\theta$ and PKC $\beta$ gradually dephosphorylated thereafter. Erk1/2 MAPK phosphorylation occurred after $30 \mathrm{~s}$ of nLDL stimulation and reached maximal phosphorylation after $3 \mathrm{~min}$ (Figure 3a). Preincubation with PKC $\beta$ and PKC $\theta$ inhibitors, Rotln and mPKC $\theta$, respectively, did not affect nLDL-stimulated Erk1/2 MAPK phosphorylation (Figure 3b). PD98059, a MEK $1 / 2$ inhibitor, also did not affect PKC $\theta$ phosphorylation at $30 \mathrm{~s}$
(Figure 3c), and neither PD98059 nor mPKC $\theta$ incubation affected PKC $\beta$ phosphorylation (Figure 3d). To determine the role of these kinases in NADPH oxidase activation, we performed immunoprecipitation with specific antiserum against p47phox, a cytosolic component of NADPH oxidase. The p47phox interacted with phospho-Erk1/2 MAPK, phospho-PKC $\theta$ and phospho-PKC $\beta$ after $2 \mathrm{~min}$ of nLDL stimulation (Figure 3e).

Erk1/2 MAPK and PKC phosphorylation induced p47phox translocation to p22phox in nLDL-stimulated hAoSMCs As shown in Figure 4a, nLDL stimulation enhanced p47phox translocation from the cytosolic fraction to the membrane fraction. Inhibition of Erk1/2 MAPK and PKC preserved p47phox in the cytosolic compartment (** vs nLDL, $P<0.05$, $n=3$ ) and blocked translocation of p47phox to the membrane. Immunofluorescence imaging revealed the localization of p47phox at the membrane with nLDL stimulation (Figure 4b) that was markedly disrupted by PD98059 and calphostin C. As shown in Figure 4c, nLDL increased p22phox 
a
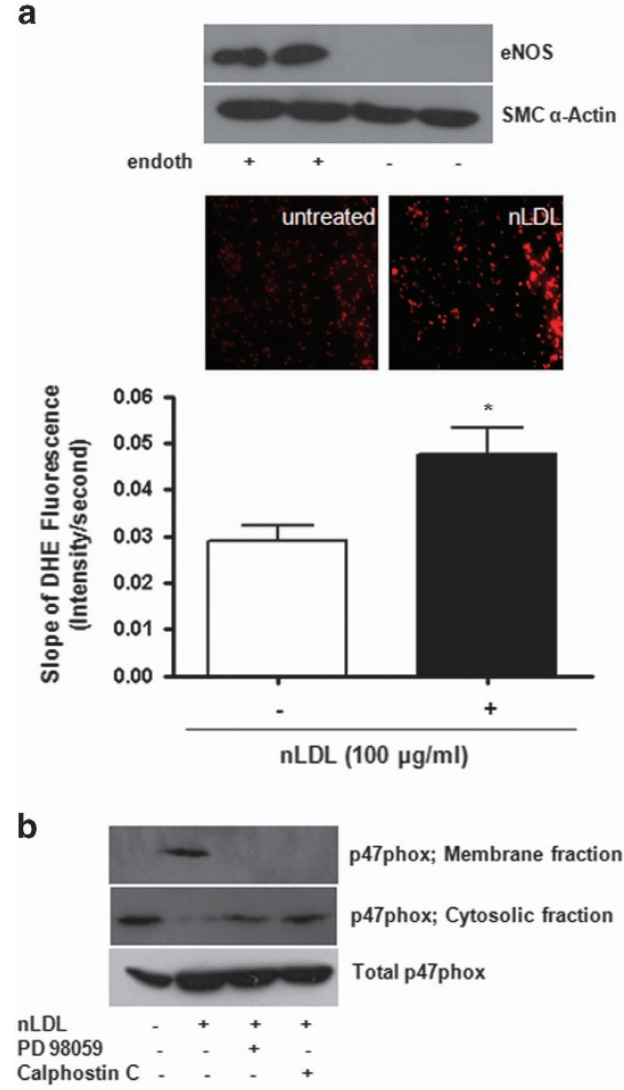
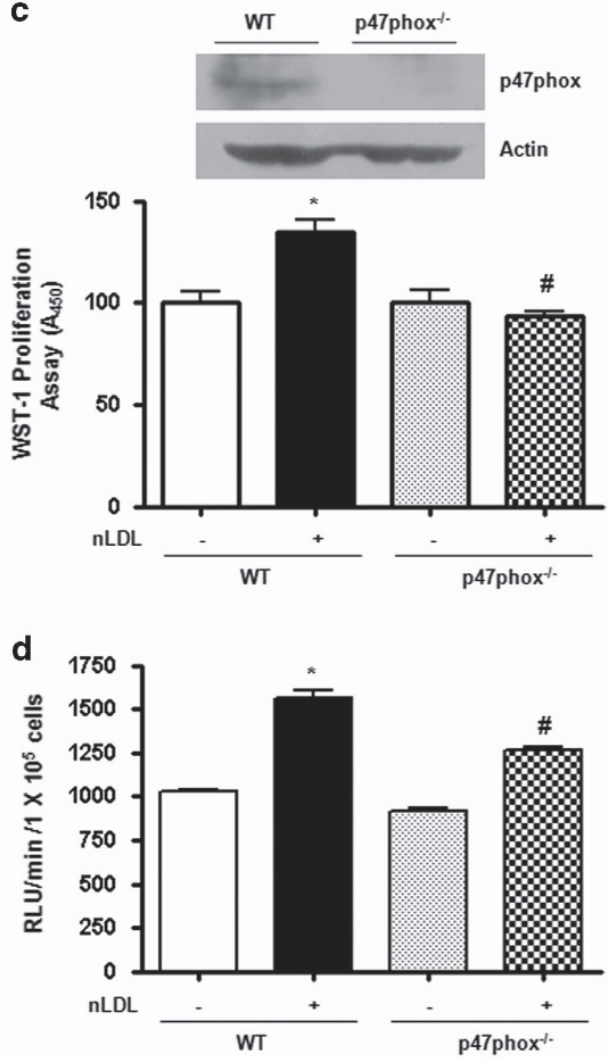

Figure 6 Native low-density lipoprotein (nLDL)-induced activation of nicotinamide adenine dinucleotide phosphate (NADPH) oxidase was associated with human aortic smooth muscle cell (hAoSMC) proliferation in deendothelialized mouse aortic rings. (a) Deendothelialized mice aortic rings were confirmed by western blot analysis using anti-serum against endothelial nitric oxide synthase (eNOS; top) and stained with the superoxide-detecting fluorescence dye dihydroethidine (DHE; middle). The effect of $n L D L$ on the slope of DHE fluorescence was measured (bottom, * vs untreated, $P<0.01, n=4)$. (b) PD98059 and calphostin $C$ prevented nLDL-stimulated p47phox movement into the membrane fraction in the deendothelialized mice aortic rings. (c) Mouse aortic smooth muscle cells (mAoSMCs) were isolated from wild type (WT) and p47phox ${ }^{-1-}$ mice. The nLDL induced proliferation in mAoSMCs from the WT mice (* vs untreated, $P<0.01, n=6$ ), but not in mAoSMCs from the p47phox ${ }^{-1-}$ mice (\# vs nLDL-treated in WT, $P<0.01, n=6$ ). (d) The nLDL-dependent reactive oxygen species (ROS) production was attenuated in mAoSMCs from the p47phox ${ }^{-1-}$ mice in a superoxide measurement assay using lucigenin (\# vs nLDL-treated in WT, $P<0.01, n=6$ ).

and p47phox protein interaction that was blocked by the inhibition of Erk1/2 MAPK and PKC, respectively. Furthermore, nLDL-induced superoxide production was completely blocked by the PKC inhibitors Rotln and mPKCO (Rotln vs nLDL, $1007 \pm 70$ vs $1346 \pm 60 \mathrm{AU} ; \mathrm{mPKC} \theta$ vs nLDL, $1017 \pm 10$ vs $1346 \pm 60 \mathrm{AU})$ and the MEK1/2 inhibitor PD98059 (PD98059 vs nLDL, $998 \pm 9$ vs $1346 \pm 60$ ), but the p38MAPK inhibitor SB203580 did not affect nLDL-dependent superoxide generation (nLDL vs SB203580, $1346 \pm 60$ vs $1335 \pm 30$, Figure $4 d)$.

NADPH oxidase-derived superoxide production by nLDL contributed to hAoSMC proliferation

To further confirm that superoxide might induce hAoSMC proliferation, we used a WST-1 reagent to perform a proliferation assay in the presence of superoxide scavenger and NADPH oxidase inhibitors (Figure 5a). Stimulation with nLDL triggered a 1.36 -fold increase in cell proliferation (* vs untreated,
$1.36 \pm 0.05$ vs $1 \pm 0.04$ ) that was reduced by preincubation with polyethylene glycol-conjugated superoxide dismutase (\# vs nLDL, $0.95 \pm 0.06$ vs $1.36 \pm 0.05$ ), apocynin (\# vs nLDL, $1.00 \pm 0.04$ vs $1.36 \pm 0.05$ ) and DPI (\# vs nLDL, $0.97 \pm 0.11$ vs $1.36 \pm 0.05)$. The siRNA transfection significantly decreased p47phox protein expression to $82 \%$ of the control level (Figure 5b, upper) that was associated with inhibited nLDLinduced proliferation (Figure 5b, lower). Furthermore, the kinase inhibitors involved in $\mathrm{p} 47$ phox translocation prevented nLDL-dependent proliferation of hAoSMCs (Figure 5c). These results indicate that nLDL stimulation of hAoSMC induces superoxide production through NADPH oxidase activation that is directly associated with hAoSMC proliferation.

The nLDL-dependent superoxide production induced proliferation in mAoSMCs

The nLDL stimulation of deendothelialized aortic rings, undetected endothelial nitric oxide synthase protein, from 
a

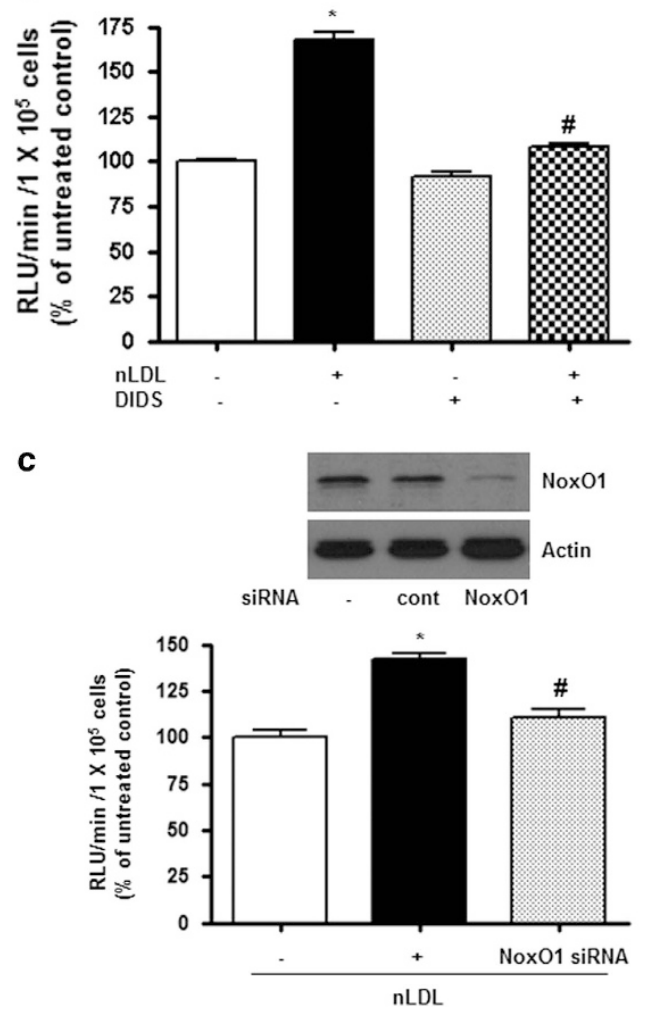

b
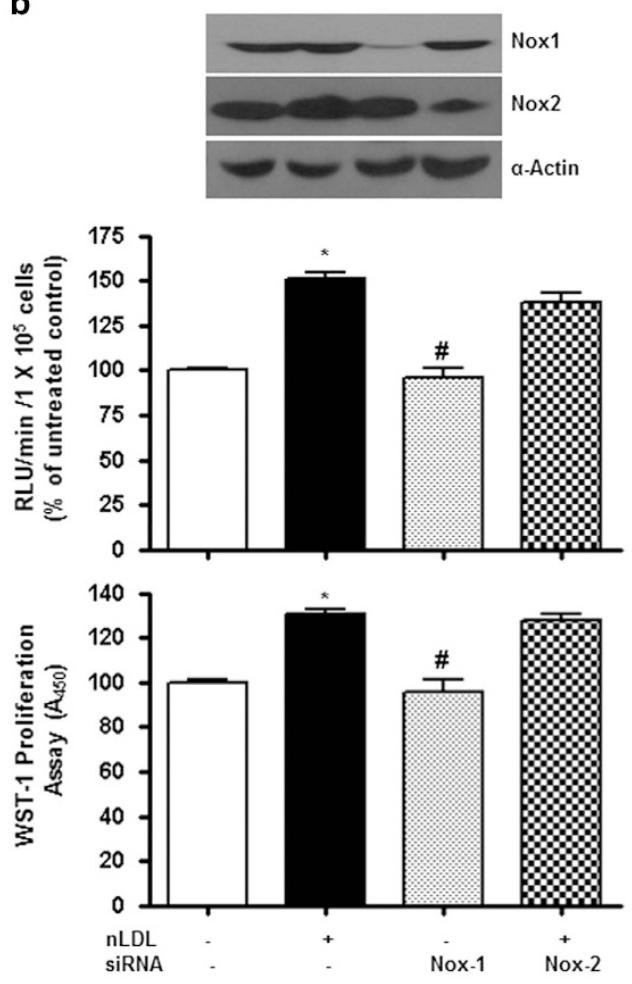

Figure 7 Nicotinamide adenine dinucleotide phosphate (NADPH) oxidase 1 (Nox1) was involved in native low-density lipoprotein (nLDL)induced superoxide generation and proliferation. (a) Human aortic smooth muscle cells (hAoSMCs) were trypsinized after the incubation of 4,4'-diisothiocyanostilbene-2,2'-disulfonic acid (DIDS; $100 \mu \mathrm{m}$ ) (as a $\mathrm{Cl}^{-}$channel inhibitor) for 30 min, and lucigenin-dependent chemiluminescence was measured with or without $\mathrm{nLDL}$ stimulation. $\mathrm{nLDL}$-induced superoxide generation was significantly blocked with DIDS incubation (* vs untreated, $P<0.01$; \# vs $n L D L, P<0.01$ ). (b) Small interfering RNAs (siRNAs) against Nox1 and Nox2 were transfected into hAoSMCs (upper), respectively, and superoxide generation (middle) and cell proliferation (lower) were measured. Decreased Nox1 protein (by siRNA transfection) was associated with the prevention of $\mathrm{nLDL}$-induced superoxide generation and cell proliferation; however, Nox2 was not involved in superoxide generation in nLDL-stimulated hAoSMCs. (c) Transfection of siRNA against NoxO1 prevented reactive oxygen species (ROS) generation in nLDL-stimulated vascular smooth muscle cells (VSMCs; * vs untreated, $P<0.01 ;$ \# vs nLDL, $P<0.05)$.

WT mice significantly increased the DHE fluorescence (Figure 6a) and DHE fluorescence slope from $0.029 \pm 0.003$ to $0.048 \pm 0.005$. Incubation of the aortic rings with $\mathrm{nLDL}$ increased p47phox membrane translocation that was blocked by co-incubation with PD98059 or calphostin C (Figure 6b). As shown in Figure $6 \mathrm{c}, \mathrm{nLDL}$ induced proliferation in mouse aortic smooth muscle cells (mAoSMCs) from the WT mice but not in those from the $\mathrm{p} 47 \mathrm{phox}^{-1-}$ mice. ROS production from nLDL stimulation was significantly attenuated in the mAoSMCs from $\mathrm{p} 47 \mathrm{phox}^{-1-}$ compared with those from the WT mice (Figure 6d).

\section{Nox1 played an important role in nLDL-induced superoxide generation}

In our previous report, DIDS (a $\mathrm{Cl}^{-}$channel blocker) inhibited nLDL-induced DNA synthesis and cell proliferation in hAoSMCs, ${ }^{9}$ and Nox1 activity was controlled by chloride channel 3 that is required for charge neutralization of the electron flow generated by Nox $1 ;^{18}$ in that report, we investigated whether Noxl was responsible for superoxide generation and proliferation in nLDL-stimulated hAoSMCs. As shown in Figure 7a, DIDS, as $\mathrm{Cl}^{-}$channel inhibitor, blocked nLDL-dependent superoxide generation (\# vs nLDL, $108 \pm 4.3$ vs $168 \pm 10.7 \%)$. Interestingly, downregulation of Nox1 protein by transient transfection of siRNA (Figure $7 \mathrm{~b}$ upper) inhibited the generation of nLDL-dependent superoxide (Figure 7b middle, \# vs nLDL, $96 \pm 12.3$ vs $151 \pm 9.7 \%$ ) as well as cell proliferation (Figure $7 \mathrm{~b}$ lower, \# vs nLDL, $92 \pm 11.3$ vs $131 \pm 5.1 \%)$. However, siRNA against Nox2 has little effect on superoxide generation and cell proliferation. Furthermore, transfection of siRNA against NoxO1 as a Nox1 organizer prevented ROS generation in nLDL-stimulated VSMCs (Figure $7 c$, \# vs nLDL, $110.6 \pm 12.3$ vs $142.0 \pm 7.7 \%$ ).

\section{DISCUSSION}

ROS have been shown to modulate vascular signaling in endothelium and smooth muscle, as well as regulate vascular hypertrophy, inflammation, remodeling, intracellular calcium 
and disturb nitric oxide bioavailability. ${ }^{19}$ Here, we demonstrate for the first time that nLDL, the primary cause of cardiovascular diseases, induced NADPH oxidase activation by stimulating p47phox membrane translocation in an Erk1/2- and PKC $\beta$ - and $\theta$-dependent manner. Increased superoxide anion from Nox1 was responsible for cellular proliferation in nLDLstimulated hAoSMCs. Furthermore, we confirmed the participation of NADPH oxidase in nLDL-stimulated proliferation using VSMCs isolated from p47phox-null mice.

Of the various sources of ROS production, NADPH oxidase is a major source of superoxide generation in both endothelial and smooth muscle cells. ${ }^{20}$ Several stimulants increase superoxide generation from NADPH oxidase and the generated ROS play key roles in the development and progression of pathophysiological conditions. $\mathrm{H}_{2} \mathrm{O}_{2}$ production activates redox-sensitive Erk1/2 ${ }^{21}$ and p38 that contribute to angiotensin II-induced VSMC proliferation. ${ }^{22} \mathrm{H}_{2} \mathrm{O}_{2}$ also mediates the mitogenic activity of growth factors such as platelet-derived growth factor ${ }^{21}$ epidermal growth factor, ${ }^{23}$ insulin $^{24}$ and oxidized LDL. ${ }^{25}$ However, platelet-derived growth factordependent superoxide induces an inflammatory response through increased expression of monocyte chemoattractant protein-1. ${ }^{26}$ However, in nLDL-stimulated hAoSMCs, as indicated in our previous study, $\mathrm{H}_{2} \mathrm{O}_{2}$ mediated the induction of interleukin-8 expression, ${ }^{16}$ an initiator of inflammatory reaction, and superoxide appeared to be important for mitogenic signaling. ${ }^{5,6}$ In this study, superoxide generation through NADPH oxidase activation was responsible for nLDLstimulated hAoSMC proliferation (Figure 5b), consistent with previous findings that demonstrated p47phox-dependent VSMC proliferation in response to mitogenic stimuli, such as serum or thrombin. ${ }^{27}$ Therefore, two different ROS families that are generated in nLDL-stimulated hAoSMCs exert different effects based on the redox imbalance mechanisms in the same cell; superoxide induces cell proliferation in this study, whereas $\mathrm{H}_{2} \mathrm{O}_{2}$ mediates inflammatory response. ${ }^{16}$ Moreover, ROS from macrophages and endothelial cells (but not VSMCs) have been shown to be the main contributor to nLDL oxidation. However, our results (Figure 1) suggest that superoxide from nLDL-activated NADPH oxidase may also contribute to nLDL oxidation. This finding is consistent with the observation that increased NADPH oxidase-dependent vascular superoxide production by hypercholesterolemia appears in the early stages of atherosclerosis. ${ }^{28}$ Therefore, increased nLDL levels may induce hAoSMC activation and then contribute to atherogenesis through the inflammatory chemokine, interleukin-8, production, ${ }^{16}$ oxidation of macromolecules and cell proliferation based on redox imbalance mechanisms.

The p47phox phosphorylation and membrane translocation is essential for NADPH oxidase activation and superoxide production. PKC phosphorylates p47phox at S359/S370/S379 that causes it to associate with p22phox..$^{29}$ The catalytic activity of NADPH oxidase is also augmented by the phosphorylation of p47phox at the S303/S304 residue, and S303A/S304A, a mutant of p47phox, suppresses the redox-sensitive signal by angiotensin II in VSMCs. ${ }^{30}$ Phosphorylation of three p47phox sites (ser303, 304 and 328) is required for the interaction of the SH3 domains with the p22phox-polyproline-rich sequence. ${ }^{31}$ The nLDL independently induced p47phox phosphorylation through Erk1/2 MAPK and PKC $\beta / \theta$ (Figure 3d); the inhibition of one of the kinases completely abrogated p47phox translocation to the membrane (Figures $4 \mathrm{a}$ and $\mathrm{c}$ ), and these phosphorylations were critical for the formation of the NADPH oxidase complex with p22phox (Figure 4b). Together, these data suggest that Erk1/2 and PKC $\beta / \theta$ activation by nLDL stimulation plays an important role in p47phox translocation and NADPH oxidase activation and contribute to VSMC proliferation.

Therefore, nLDL (as a mitogen) increased superoxide production in both hAoSMCs and isolated mouse aorta by activating Erk1/2 MAPK and $\mathrm{PKC} \beta / \theta$ that led to p47phox translocation and, subsequently, NADPH oxidase activation. This mechanism provides a potential target for preventing VSMC proliferation under hypercholesterolemic conditions.

\section{CONFLICT OF INTEREST}

The authors declare no conflict of interest.

\section{ACKNOWLEDGEMENTS}

This study was supported by the Basic Science Research Program of the National Research Foundation of Korea (NRF) that is funded by the Ministry of Education, Science and Technology (2012-0006812 to SR and 2012-0005766 to BHJ).

1 Ross R. Atherosclerosis-an inflammatory disease. N Engl J Med 1999; 340: 115-126.

2 Castelli WP. Epidemiology of coronary heart disease: the Framingham study. Am J Med 1984; 76: 4-12.

3 Auge N, Maupas-Schwalm F, Elbaz M, Thiers JC, Waysbort A, Itohara S et al. Role for matrix metalloproteinase-2 in oxidized low-density lipoprotein-induced activation of the sphingomyelin/ceramide pathway and smooth muscle cell proliferation. Circulation 2004; 110: 571-578.

4 Watanabe T, Pakala R, Koba S, Katagiri T, Benedict CR. Lysophosphatidylcholine and reactive oxygen species mediate the synergistic effect of mildly oxidized LDL with serotonin on vascular smooth muscle cell proliferation. Circulation 2001; 103: 1440-1445.

5 Heo KS, Kim DU, Ryoo S, Nam M, Baek ST, Kim L et al. PPARgamma activation abolishes LDL-induced proliferation of human aortic smooth muscle cells via SOD-mediated down-regulation of superoxide. Biochem Biophys Res Commun 2007; 359: 1017-1023.

6 Locher R, Brandes RP, Vetter W, Barton M. Native LDL induces proliferation of human vascular smooth muscle cells via redox-mediated activation of ERK 1/2 mitogen-activated protein kinases. Hypertension 2002; 39 : 645-650.

7 Sachinidis A, Mengden T, Locher R, Brunner C, Vetter W. Novel cellular activities for low density lipoprotein in vascular smooth muscle cells. Hypertension 1990; 15: 704-711.

$8 \mathrm{Heo}$ KS, Kim DU, Kim L, Nam M, Baek ST, Park SK et al. Activation of PKCbeta(II) and PKCtheta is essential for LDL-induced cell proliferation of human aortic smooth muscle cells via Gi-mediated Erk1/2 activation and Egr-1 upregulation. Biochem Biophys Res Commun 2008; 368: 126-131.

9 Heo KS, Ryoo SW, Kim L, Nam M, Baek ST, Lee H et al. Cl- -channel is essential for LDL-induced cell proliferation via the activation of Erk $1 / 2$ and $\mathrm{PI3k} / \mathrm{Akt}$ and the upregulation of Egr-1 in human aortic smooth muscle cells. Mol Cells 2008; 26: 468-473. 
10 Lassegue B, Clempus RE. Vascular NAD(P)H oxidases: specific features, expression, and regulation. Am J Physiol Regul Integr Comp Physiol 2003; 285: R277-R297.

11 Seshiah PN, Weber DS, Rocic P, Valppu L, Taniyama Y, Griendling KK. Angiotensin II stimulation of $\mathrm{NAD}(\mathrm{P}) \mathrm{H}$ oxidase activity: upstream mediators. Circ Res 2002; 91: 406-413.

12 Zafari AM, Ushio-Fukai M, Akers M, Yin Q, Shah A, Harrison DG et al. Role of NADH/NADPH oxidase-derived $\mathrm{H} 2 \mathrm{O} 2$ in angiotensin II-induced vascular hypertrophy. Hypertension 1998; 32: 488-495.

13 Grote K, Flach I, Luchtefeld M, Akin E, Holland SM, Drexler $\mathrm{H}$ et al. Mechanical stretch enhances mRNA expression and proenzyme release of matrix metalloproteinase-2 (MMP-2) via NAD(P)H oxidase-derived reactive oxygen species. Circ Res 2003; 92: e80-e86.

14 Ungvari Z, Csiszar A, Huang A, Kaminski PM, Wolin MS, Koller A. High pressure induces superoxide production in isolated arteries via protein kinase C-dependent activation of NAD(P)H oxidase. Circulation 2003; 108 1253-1258.

15 Touyz RM, Schiffrin EL. Increased generation of superoxide by angiotensin II in smooth muscle cells from resistance arteries of hypertensive patients: role of phospholipase D-dependent $\mathrm{NAD}(\mathrm{P}) \mathrm{H}$ oxidase-sensitive pathways. J Hypertens 2001; 19: 1245-1254.

16 Ryoo SW, Kim DU, Won M, Chung KS, Jang YJ, Oh GT et al. Native LDL induces interleukin-8 expression via H2O2, p38 Kinase, and activator protein-1 in human aortic smooth muscle cells. Cardiovasc Res 2004; 62 185-193.

17 Ryoo S, Gupta G, Benjo A, Lim HK, Camara A, Sikka G et al. Endothelial arginase II: a novel target for the treatment of atherosclerosis. Circ Res 2008; 102: 923-932.

18 Miller FJ Jr., Filali M, Huss GJ, Stanic B, Chamseddine A, Barna TJ et al. Cytokine activation of nuclear factor kappa B in vascular smooth muscle cells requires signaling endosomes containing Noxl and CIC-3. Circ Res 2007; 101: 663-671.

19 Griendling KK, Sorescu D, Lassegue B, Ushio-Fukai M. Modulation of protein kinase activity and gene expression by reactive oxygen species and their role in vascular physiology and pathophysiology. Arterioscler Thromb Vasc Biol 2000; 20: 2175-2183.

20 Zalba G, Beaumont FJ, San Jose G, Fortuno A, Fortuno MA, Etayo JC et al. Vascular NADH/NADPH oxidase is involved in enhanced superoxide production in spontaneously hypertensive rats. Hypertension 2000; 35: 1055-1061.

21 Sundaresan M, Yu ZX, Ferrans VJ, Irani K, Finkel T. Requirement for generation of $\mathrm{H} 2 \mathrm{O} 2$ for platelet-derived growth factor signal transduction. Science 1995; 270: 296-299.

22 Ushio-Fukai M, Alexander RW, Akers M, Griendling KK. p38 Mitogenactivated protein kinase is a critical component of the redox-sensitive signaling pathways activated by angiotensin II. Role in vascular smooth muscle cell hypertrophy. J Biol Chem 1998; 273: 15022-15029.
23 Lee SR, Kwon KS, Kim SR, Rhee SG. Reversible inactivation of proteintyrosine phosphatase 1B in A431 cells stimulated with epidermal growth factor. J Biol Chem 1998; 273: 15366-15372.

24 Mahadev K, Zilbering A, Zhu L, Goldstein BJ. Insulin-stimulated hydrogen peroxide reversibly inhibits protein-tyrosine phosphatase $1 \mathrm{~b}$ in vivo and enhances the early insulin action cascade. J Biol Chem 2001; 276: 21938-21942.

25 Yin CC, Huang KT. H2O2 but not 02- elevated by oxidized LDL enhances human aortic smooth muscle cell proliferation. J Biomed Sci 2007; 14: 245-254.

26 Marumo T, Schini-Kerth VB, Fisslthaler B, Busse R. Platelet-derived growth factor-stimulated superoxide anion production modulates activation of transcription factor NF-kappaB and expression of monocyte chemoattractant protein 1 in human aortic smooth muscle cells. Circulation 1997; 96: 2361-2367.

27 Barry-Lane PA, Patterson C, van der Merwe M, Hu Z, Holland SM, Yeh ET et al. p47phox is required for atherosclerotic lesion progression in ApoE (-/-) mice. J Clin Invest 2001; 108: 1513-1522.

28 Warnholtz A, Nickenig G, Schulz E, Macharzina R, Brasen JH, Skatchkov M et al. Increased NADH-oxidase-mediated superoxide production in the early stages of atherosclerosis: evidence for involvement of the reninangiotensin system. Circulation 1999; 99: 2027-2033.

$29 \mathrm{Ni}$ W, Zhan Y, He H, Maynard E, Balschi JA, Oettgen P. Ets-1 is a critical transcriptional regulator of reactive oxygen species and p47(phox) gene expression in response to angiotensin II. Circ Res 2007; 101: 985-994.

30 Adachi T, Pimentel DR, Heibeck T, Hou X, Lee YJ, Jiang B et al. S-glutathiolation of Ras mediates redox-sensitive signaling by angiotensin II in vascular smooth muscle cells. J Biol Chem 2004; 279. 29857-29862.

31 Shiose A, Sumimoto $\mathrm{H}$. Arachidonic acid and phosphorylation synergistically induce a conformational change of $\mathrm{p} 47 \mathrm{phox}$ to activate the phagocyte NADPH oxidase. J Biol Chem 2000; 275: 13793-13801.

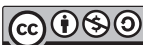

This work is licensed under a Creative Commons Attribution-NonCommercial-ShareAlike 4.0 International License. The images or other third party material in this article are included in the article's Creative Commons license, unless indicated otherwise in the credit line; if the material is not included under the Creative Commons license, users will need to obtain permission from the license holder to reproduce the material. To view a copy of this license, visit http:// creativecommons.org/licenses/by-nc-sa/4.0/ 